\title{
Application of IMC-PID Controller with Integer- order Filter and Fractional-order Filter for Steam Distillation Essential Oil Extraction Process
}

\author{
Siti Nur Hasinah Johari, Ramli Adnan, and Mazidah Tajjudin
}

\begin{abstract}
Essential oils are one of the main compounds in the pharmaceutical, fragrance and food industries. Essential oils are volatile and sensitive to heat. They can be extracted using various methods and including steam distillation which is regarded in this research. Consequently, the temperature during the extraction process is an important factor that influences the quality of essential oils. For decades the famous PID controller dominated the industrial control loop. Poor PID control tuning may result in poor control performance and even poor quality products. This study proposes an Internal Model Control (IMC) tuning method for a PID controller to control steam temperature during the extraction process. IMC suggested a model based tuning rules so that the closed-loop will be less sensitive to disturbance. Two types of IMCPID controller approaches were considered in this paper which are IMC-PID controller with integer-order filter (IOF) and IMC-PID controller with fractional-order filter (FOF). There is a single tuning parameter in IO filter, while the FO filter has two parameters to be tuned in order to achieve satisfactory response of the system. The simulation is done in Simulink using MATLAB R2018a and comparison studies are made for transient response ( Tr, Ts, \%Mp) for both controllers. The result has shown that the IMC-PID FOF controller gives a better response than IMC-PID IOF controller by having less overshoot $(2.59 \%)$ and has fastest rise time and settling time by $264.7 \mathrm{~s}$ and $447.4 \mathrm{~s}$ respectively.
\end{abstract}

Keywords-Essential Oils Extraction, Steam Distillation, IMCPID controller, Fractional-order filter, Integer-order filter

\section{INTRODUCTION}

For its charming signature, an essential oils are known and mostly used in fragrance campaigns. Several factors will determine the quality of the essential oils, and one factor is the temperature during the extraction process[1]-[3]. Temperature control is an important issue that must always be controlled to avoid any hazard during extraction and to control the quality of essential oils. This is because the essential oils cannot be extracted when the temperature is too low while when the temperature is too high it destroys the chemical compound inside the essential oils[4].

This manuscript is submitted on $10^{\text {th }}$ February 2020 and accepted on $16^{\text {th }}$ June 2020. Siti Nur Hasinah Johari, Ramli Adnan and Mazidah Tajjudin are with the Faculty of Electrical Engineering, Universiti Teknologi MARA, 40450 Shah Alam, Selangor (e-mail: hasinahjohari@gmail.com)

1985-5389/C 2021 The Authors. Published by UiTM Press. This is an open access article under the CC BY-NC-ND license (http://creativecommons.org/ licenses/by-nc-nd/4.0/).
Temperatures required for optimal steam distillation typically falls between $60^{\circ} \mathrm{C}$ and $100^{\circ} \mathrm{C}$ [5]. However, it depends on the plant material and oil type. In this study, steam distillation for essential oils extraction (SDEOE) process is applied. The technique of steam distillation can purify or isolate delicate products such as natural aromatic compounds, where steam is injected to release aromatic molecule into the plant. Indeed, compared to other methods, this technique can extract essential oils by nearly 93 percent [1], [6]. In addition, the benefit of steam distillation is that it can accurately regulate and adjust the temperature to guarantee that the system stays within the optimum temperature range continuously. It also has a low cost scheme, enhanced productivity and low operating costs resulting in the prefer ability of the industry [7], [8]

In steam temperature control for steam distillation, the Proportional Integral Derivative (PID) controller is still the most common and efficient way. However, when the PID controller is tuned using rule-based methods, the control loop becomes sensitive to disturbance and changes in parameters, resulting in an unwanted result [6]. To encounter the problem, the PID controller can be tuned by using Internal Model Control (IMC) method. This tuning method simplifies the traditional control structure by inserting the plant model into its control loop. To achieve perfect control of the system, the IMC controller is the inverse of the process model multiply with filter function in this case integer order filter and fractional order filter[9].IMC is one of the well-known model-based controls due to its simplicity, excellent control quality and as a consequence it has discovered broad acceptance within process control [10].

The first application of IMC was presented by Daniel et al. on the continuous distillation plant in 1980s [11]. As the pioneer in the IMC, they had demonstrated the IMC design in many process model such as the first-order process with time delay and integrating process. The IMC-PID tuning rules have the advantage of using only a one tuning parameter to achieve a simple trade-off against model inaccuracies between closed-loop efficiency and robustness The IMC-PID controller provides good set-point tracking but shows slow responses to disturbances, especially for processes with small time-delay/time-constant ratios [11]-[13].However, since disturbance rejection is often more critical than set-point tracking, designing a controller with 
better disturbance rejection rather than set-point tracking is an important problem that many current work aims to solve.

Li et al. [14] proposed an IMC-based PID cascade control of superheated steam temperature. In their work, they obtained the process model of superheated steam temperature by identify the changing of set-point in the inner and outer control loop. Then the IMC-based PID controller was designed using internal model control (IMC) and improve the design by using the SkogestadIMC tuning method that was proposed in [15]. The result of their study shows that the proposed design able to eliminate the disturbance effectively. This application show that the proposed IMC-based PID cascade control provides better performance than PID controller.

Recently, a new methodology in IMC controller had been proposed to use a fractional-order filter instead of the integerorder filter. Over the past two decades, controllers of fractionalorder proportional-integral-derivative (FOPID) had received considerable attention. In controller design, they provide more flexibility compared to conventional PID controllers. This is because the conventional PID controllers have to pick five parameters instead of three parameters [16]. This flexibility, however, also means that controller tuning can be much more complicated. IMC-PID FOF controller design applies the CRONE principle that proposed by Oustaloup [17].

The first control design of IMC-PID FOF was proposed by Bettayeb and Mansouri [16], [18]. The fractional property is not specifically by the controller structure but by the reference model of the closed loop. This becomes their main reason to design this controller. Many industries can use this controller approach as their controller design. An improvement of IMC-PID FOF controller design proposed by Ranganayakulu et al. for noninteger order plus time delay process (NIOPTD) [19]. Instead using first-order Pade' approximation proposed by [11], they used higher order Pade's approximation which it is major contribution to their findings. The findings suggest that the closed loop system is robustly stable with the proposed controller.

The objective of this paper is to make a comparative study between IMC-PID controller with integer-order and fractionalorder filters in regulating the steam temperature of an SDEOE system.

\section{METHODOLOGY}

\section{A. Steam Distillation pot}

Figure 1 shows the schematic apparatus of SDEOE process being considered in this study. The steam from the boiled water is passed through the raw material. Heat from the steam will break down the pores of the raw material and extract the essential oils from it. This vapor content is then condensed and the essential oils can be separated. It should be noted that chemical compounds in the essential oil are unique and they have specific boiling point. Prior knowledge on these temperature ranges is crucial before the extraction takes place.

\section{B. Steam Temperature Process Model}

Steam temperature process model for essential oils extraction process has been obtained from aprevious research [6]. According to Mazidah et al the process can be modelled by a linear transfer function such as first-order plus dead time model, FOPDT. The general equation of FOPDT is represented by (1) where $K_{p}, \tau_{p}$ and $\theta$ are process gain, process time constant and dead-time respectively.

$$
\mathrm{G}(\mathrm{s})=\frac{\mathrm{K}_{\mathrm{p}}}{\left(\tau_{\mathrm{p}} \mathrm{s}+1\right)} \mathrm{e}^{-\theta \mathrm{s}}
$$

Therefore, the FOPDT mathematical model representation for steam temperature was stated in [20] as below,

$$
G(s)=\frac{4.5}{\left(280_{s}+1\right)} e^{-25 s}
$$

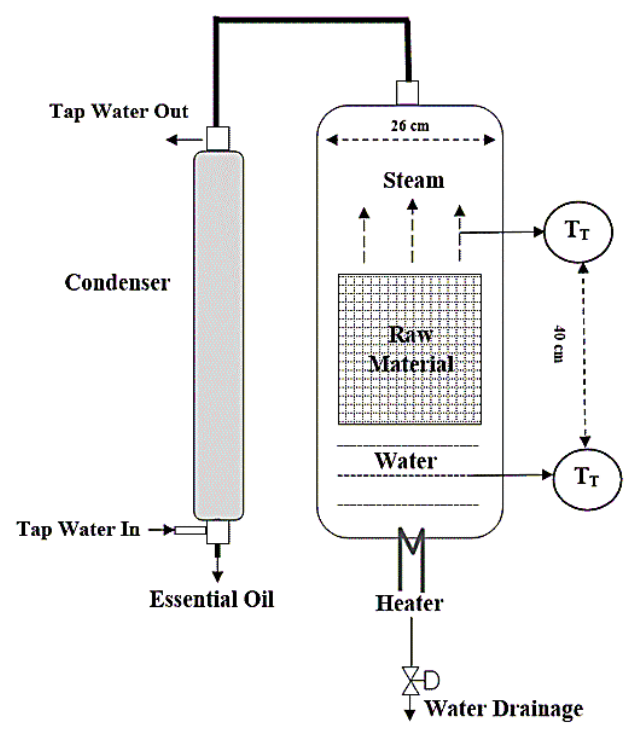

Figure 1: Schematic Diagram of Steam Distillation Process

\section{Internal Model Control (IMC)}

The ones who introduced a comprehensive structure of IMC were Morari and coworkers back in 1980s [11], [21], [22]. In [11], the theoretical framework and implementation that could use IMC were presented. Additionally, IMC was designed in 2 parts, the first being the internal model itself. The internal model's purposes are to predict the process reaction and to achieve the control goals where the manipulated variable is adjusted. The second part was the filter where the controller structure needed to achieve the required robustness.

In the block diagram shown in Figure 2 [23], IMC application is provided for the $\mathrm{G}(\mathrm{s})$ process transfer function. A process model , $g_{p}(s)$ and the controller output $u(s)$ are used to calculate the output model response, $\widetilde{y}(\mathrm{~s})$. The IMC controller is $\mathrm{q}(\mathrm{s}), \widetilde{\mathrm{g}}_{\mathrm{p}}(\mathrm{s})$ is the model of the process which is subtracted from the plant output response $y(s)$. The input signal is $r(s), \widetilde{r}(s)$ is the error, $\mathrm{d}(\mathrm{s})$ is the actual disturbance and $\widetilde{\mathrm{d}}(\mathrm{s})$ is the plant disturbance. In Figure 3, the traditional feedback controller block diagram is displayed. It can be shown that these two block diagrams are identical if controller $\mathrm{q}(\mathrm{s})$ and $\mathrm{c}(\mathrm{s})$ satisfy the relation,

$$
\mathrm{G}_{\mathrm{c}}(\mathrm{s})=\frac{\mathrm{q}(\mathrm{s})}{1-\widetilde{g}_{\mathrm{p}}(\mathrm{s}) \mathrm{q}(\mathrm{s})}
$$


Any q(s) IMC controller is therefore identical to a traditional c(s) feedback controller, and vice versa.

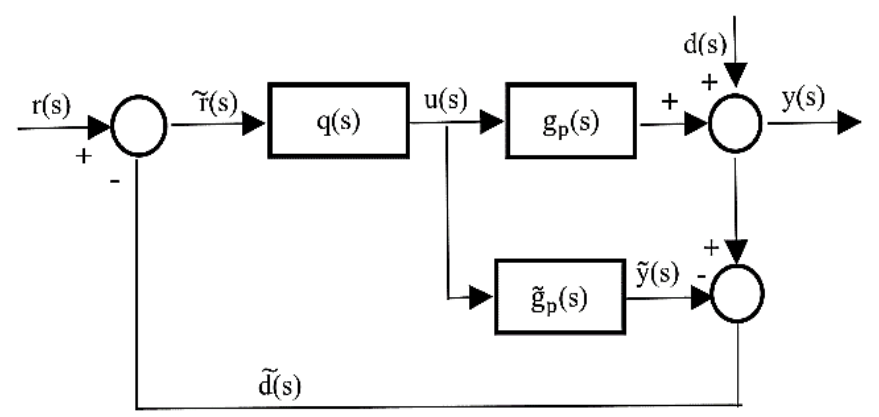

Figure 2: Block diagram of IMC structure

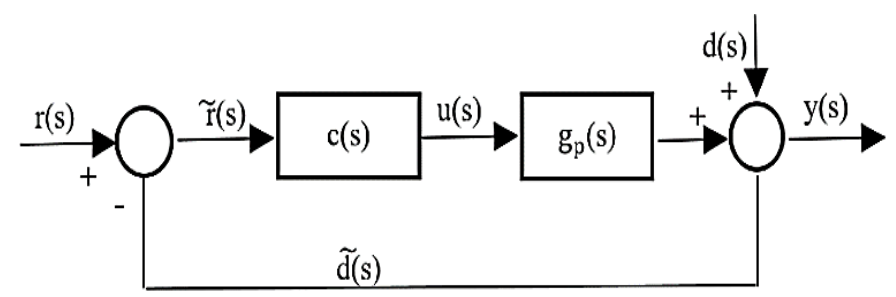

Figure 3: Conventional Block Diagram of PID

\section{IMC-PID Integer-order Filter Controller Design}

The objective of the design is to have a less sensitive toward parameter changes in the control system. The closed-loop functions need to be derived for the system. From (1), by replacing the dead-time the first-order Pade' approximation feature indicated by [12],

$$
\mathrm{e}^{-\theta \mathrm{s}}=\frac{1-\frac{\theta}{2} \mathrm{~s}}{1+\frac{\theta}{2} \mathrm{~s}}
$$

Substitute (4) into (1),

$$
\tilde{\mathrm{g}}_{\mathrm{p}}(\mathrm{s})=\frac{\mathrm{K}_{\mathrm{p}} \mathrm{e}^{-\theta \mathrm{s}}}{\tau_{\mathrm{p}} \mathrm{s}+1} \approx \frac{\mathrm{K}_{\mathrm{p}}(-0.5 \theta \mathrm{s}+1)}{\left(\tau_{\mathrm{p}} \mathrm{s}+1\right)(0.5 \theta \mathrm{s}+1)}
$$

The comparative role of model transfer indicated in (5) can be factorized into the invertible and non-invertible component as shown below,

$$
\begin{gathered}
\tilde{g}_{p-}(s)=\frac{k_{p}}{\left(T_{p} s+1\right)(0.5 \theta s+1)} \\
\tilde{g}_{p^{+}}(s)=-0.5 \theta s+1
\end{gathered}
$$

Daniel et al [11] stated that to achieve a perfect IMC controller, the inverse of the process model multiplying the filter function $\mathrm{f}(\mathrm{s})$ from the optimal controller. The role of filter function $\mathrm{f}(\mathrm{s})$ is to achieve controller stability. This is where the difference between IMC-PID with integer-order filter and IMCPID with fractional-order filter (see details in section E for IMCPID with Fractional-order filter design).

The transfer function $\mathrm{f}(\mathrm{s})$ of integer-order filter is provided by,

$$
f(s)=\frac{1}{\lambda s+1}
$$

Therefore, perfectIMC controller with integer-order filter is,

$$
\begin{gathered}
\mathrm{q}(\mathrm{s})=\tilde{\mathrm{q}}(\mathrm{s}) \mathrm{f}(\mathrm{s})=\tilde{\mathrm{g}}_{\mathrm{p}-}^{-1}(\mathrm{~s}) \mathrm{f}(\mathrm{s}) \\
\mathrm{q}(\mathrm{s})=\frac{\left(\tau_{\mathrm{p}} \mathrm{s}+1\right)(0.5 \theta \mathrm{s}+1)}{\mathrm{k}_{\mathrm{p}}} \frac{1}{\lambda \mathrm{s}+1}
\end{gathered}
$$

where $\lambda$ is the time constant of the closed loop. The conversion was then used to discover the conventional feedback controller equivalent. Recalling that from (3),

$$
\begin{aligned}
& g_{c}(s)=\frac{q(s)}{1-\tilde{g}_{p}(s) q(s)}=\frac{\tilde{q}(s) f(s)}{1-\tilde{g}_{p}(s) \tilde{q}(s) f(s)} \\
& g_{c}(s)=\frac{1}{k_{p}} \frac{\left(\tau_{p} s+1\right)(0.5 \theta s+1)}{(\lambda+0.5 \theta) s}
\end{aligned}
$$

Expanding the numerator term in (9).

$$
\mathrm{g}_{\mathrm{c}}(\mathrm{s})=\frac{1}{\mathrm{k}_{\mathrm{p}}} \frac{0.5 \tau_{\mathrm{p}} \theta \mathrm{s}^{2}+\left(\tau_{\mathrm{p}}+0.5 \theta\right) \mathrm{s}+1}{(\lambda+0.5 \theta) \mathrm{s}}
$$

Then by comparing (10) with the optimal PID controller represented which presented below where the PID parameter such as $\mathrm{K}_{\mathrm{c}}$ is the gain, $\tau_{\mathrm{i}}$ is the integral time constant and $\tau_{\mathrm{d}}$ is derivative time constant.,

$$
\mathrm{G}_{\mathrm{c}}(\mathrm{s})=\mathrm{K}_{\mathrm{c}}\left[1+\frac{1}{\tau_{\mathrm{i}} \mathrm{s}}+\tau_{\mathrm{d}} \mathrm{s}\right]
$$

The parameters of the controller are shown below,

$$
\begin{aligned}
& \mathrm{K}_{\mathrm{c}}=\frac{\left(\tau_{\mathrm{p}}+0.5 \theta\right)}{\mathrm{k}_{\mathrm{p}}(\lambda+0.5 \theta)} \\
& \tau_{\mathrm{i}}=\tau_{\mathrm{p}}+0.5 \theta \\
& \tau_{\mathrm{d}}=\frac{\tau_{\mathrm{p}} \theta}{2 \tau_{\mathrm{P}}+\theta}
\end{aligned}
$$

The $\lambda$ (closed loop time constant) is the tuning parameter of the optimal IMC-based PID controller where recommended value for $\lambda>0.8 \theta$ because of the model uncertainty due to the Pade approximation[9].

\section{E. IMC-PID Fractional-order-filter controller design}

The IMC PID derivation with fractional-order filter from [16] will be discussed in this section. The purpose of this controller design is to have an integer-order PID that is cascaded to satisfy the requirements of the closed loop with a fractional-order filter. The derivation is the same as IMC-PID controller design previously. The only difference is the filter chosen to cascade with the controller. From (11), the controller overall equation is provided by,

$$
\mathrm{G}_{\mathrm{c}}(\mathrm{s})=\mathrm{K}_{\mathrm{c}}\left[1+\frac{1}{\tau_{\mathrm{i}} \mathrm{s}}+\tau_{\mathrm{d}} \mathrm{s}\right] \cdot \mathrm{h}(\mathrm{s})
$$


where $h(s)$ is a fractional-order filter. This study applies CRONE principle where Bode [24] suggested an ideal shape of an open loop transfer function in the form,

$$
\mathrm{L}_{\mathrm{s}}=\frac{1}{\tau_{\mathrm{c}} \mathrm{s}^{\alpha}}, \quad \alpha \epsilon \mathbb{R}^{+}
$$

where $\tau_{\mathrm{c}}$ is the time constant, $\alpha$ is the slope of the magnitude and the gain crossover frequency is,

$$
\omega_{\mathrm{c}}=\frac{1}{\tau_{\mathrm{c}}^{-\alpha}} \quad,\left|\mathrm{L}\left(\omega_{\mathrm{c}}\right)\right|=1
$$

The $\alpha$ parameter is on the log-log scale, can assumes both the integer and non-integer value. The value of $\alpha$ in the $\mathrm{L}(\mathrm{s})$ transfer function is a fractional order integrator if $\alpha<0$ and a fractional differentiator if $\alpha>0$. The bode diagram is straightforward werethe amplitude curve is a line of steady slope $-20 \alpha \mathrm{dB} / \mathrm{dec}$ where the phase margin can be extracted as in (16).

$$
\pi(1-\alpha / 2)
$$

The desired closed loop transfer function is given by,

$$
\mathrm{h}(\mathrm{s})=\frac{\mathrm{L}(\mathrm{s})}{1+\mathrm{L}(\mathrm{s})}=\frac{1}{1+\tau_{\mathrm{c}} \mathrm{s}^{\alpha+1}}, \alpha \epsilon \mathbb{R}^{+}
$$

Equation (17) is used as a reference model for tuning the controller $\mathrm{G}_{\mathrm{C}}(\mathrm{s})$. Based on this reference model, the overshoot of the system depends on the value of $\alpha$ and the settling time which depends on $\tau_{\mathrm{c}}$ can be determined respectively [25].

The open loop transfer function of the system is similar to $\mathrm{L}(\mathrm{s})$, therefore closed loop response of the system should behave like the closed loop of the reference system $h(s)$ which gives the desirable property of being insensitive to parameters changes and the step response shows the iso-damping robustness property. To obtain the iso-damping properties describe the fractional filter, $\mathrm{h}(\mathrm{s})$ given in (17), where the time constant $\tau_{\mathrm{c}}$ and non-integer differentiator parameter of fractional order, $\alpha$ are chosen to affect the phase margin and crossover gain frequency, $\omega_{\mathrm{c}}$ of closed loop system given by (18).

$$
\begin{gathered}
\tau_{\mathrm{c}}=\frac{1}{\omega_{\mathrm{c}}{ }^{\alpha+1}} \\
\alpha=\frac{\pi-\varphi_{\mathrm{m}}}{\frac{\pi}{2}}
\end{gathered}
$$

In order to calculate the fractional-order filter parameter, a method called Oustaloup's Recursive Algorithm (ORA) is used [26]. Figure 4 shows the few orders fractional differentiators and integrator with number of order, $\mathrm{N}=4$. The magnitude curve shows behaviour of a low-pass and high-pass filter for the integrator and differentiator respectively.

From (9), substitute f(s) with h(s) given in (17) as below,

$$
g_{c}(s)=\frac{q(s)}{1-\tilde{g}_{p}(s) q(s)}=\frac{\tilde{q}(s) h(s)}{1-\tilde{g}_{p}(s) \tilde{q}(s) h(s)}
$$

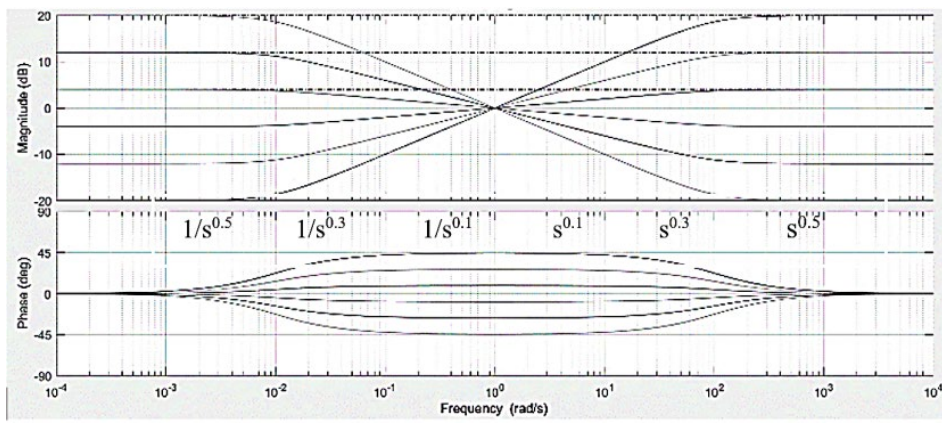

Figure 4: Fractional-order differ-integrators approximation using ORA method with $\mathrm{N}=4$

The IMC controller with fractional-order filter $\mathrm{h}(\mathrm{s})$ is provided by,

$$
\mathrm{q}(\mathrm{s})=\tilde{\mathrm{q}}(\mathrm{s}) \mathrm{h}(\mathrm{s})=\tilde{\mathrm{g}}_{\mathrm{p}-}^{-1}(\mathrm{~s}) \mathrm{h}(\mathrm{s})
$$

Hence, the IMC controller with fractional-order filter is given by,

$$
q(s)=\frac{\left(1+\tau_{p} s\right)(1+0.5 \theta)}{k_{p}}\left[\frac{1}{\left(1+\tau_{c} s^{\alpha+1}\right)}\right]
$$

Substitute (21) into (19) and expand the equation to get (22),

$$
\begin{aligned}
& g_{c}(s)=\frac{\left(1+\tau_{p} s\right)(1+0.5 \theta)}{k_{p}\left(1+\tau_{c} s^{\alpha+1}\right)} \\
& g_{c}(s)=\frac{0.5 \tau_{p} s^{2}+\left(0.5+\tau_{p}\right) s+1}{k\left(\tau_{c} s^{\alpha}+0.5 \theta\right) s}
\end{aligned}
$$

Compare (22) to (11) to get the ideal PID controller as below,

$$
\mathrm{G}_{\mathrm{c}}(\mathrm{s})=\frac{1}{1+\frac{2 \tau_{\mathrm{c}}}{\theta} \mathrm{s}^{\alpha}} \frac{2 \tau_{\mathrm{p}}+\theta}{\mathrm{k}_{\mathrm{p}} \theta}\left(1+\frac{1}{\frac{2 \tau_{\mathrm{p}}+\theta}{2}} \mathrm{~s}+\frac{\tau_{\mathrm{p}} \theta}{2 \tau_{\mathrm{p}}+\theta} \mathrm{s}^{2}\right)
$$

Hence, the tuning parameter of an ideal PID controller based IMC strategy can be obtain by,

$$
\begin{gathered}
\mathrm{K}_{\mathrm{c}}=\frac{2 \tau_{\mathrm{p}}+\theta}{\mathrm{k}_{\mathrm{p}} \theta} \\
\tau_{\mathrm{i}}=\frac{2 \tau_{\mathrm{p}}+\theta}{2} \\
\tau_{\mathrm{d}}=\frac{\tau_{\mathrm{p}} \theta}{2 \tau_{\mathrm{p}}+\theta}
\end{gathered}
$$

\section{RESULTS AND DISCUSSION}

\section{A. IMC-PID Controller}

Based on the IMC-based PID design procedure, there is the closed-loop time constant, $\lambda$ that manipulates the gain parameter, $\mathrm{K}_{\mathrm{c}}$. Therefore, there are various numbers for $\lambda$ to meet the desired performances of IMC-based PID. When the value $\lambda$ is higher, a longer settling times take and larger maximum deviations from the set-point. Table I shows the selected range of $\lambda$ which is 0.5 
to 2.0 where recommended value also include in the range to see the step performance in MATLAB Simulink. Only Proportional gain parameter $\mathrm{K}_{\mathrm{c}}$ value changes due to effect of $\lambda$ while Integral gain parameter $\tau_{\mathrm{i}}$ and Derivative gain parameter $\tau_{\mathrm{d}}$ remain the same.

TABLE I

THE RANGE OF $\lambda$ FOR IMC-BASED PID TUNING METHOD

\begin{tabular}{|c|c|c|c|}
\hline $\boldsymbol{\Lambda}$ & $\mathbf{K}_{\mathbf{c}}$ & $\boldsymbol{\tau}_{\mathbf{i}}$ & $\boldsymbol{\tau}_{\mathbf{d}}$ \\
\hline $\boldsymbol{\lambda}=\mathbf{0 . 5 \theta}$ & 2.60 & 292.5 & 11.9 \\
\hline $\boldsymbol{\lambda}=\mathbf{0 . 8 \theta}$ & 2.00 & 292.5 & 11.9 \\
\hline $\boldsymbol{\lambda}=\mathbf{1 . 5 \theta}$ & 1.30 & 292.5 & 11.9 \\
\hline $\boldsymbol{\lambda}=\mathbf{2 . 0 \theta}$ & 1.04 & 292.5 & 11.9 \\
\hline
\end{tabular}

Figure 5 shows the step response of IMC-based PID with saturation control signal level of $0-5 \mathrm{~V}$ for $\lambda=0.5 \theta, \lambda=0.8 \theta, \lambda=$ $1.5 \theta$ and $\lambda=2.0 \theta$. When the value of $\lambda$ increases, the step response gives smooth performance but slower in settling time and increasing of overshoot. Table II summarizes the transient response of the closed-loop system. From this table, it can be observed that overshoot is bigger and has a slower settling time with $\lambda=2.0 \theta$ compared to other values of $\lambda$. However, it gives a smooth step response. Therefore, due to its characteristic, $\lambda=2.0 \theta$ is chosen as the tuning rule for IMC-PID controller and compare to IMC-PID FOF. The comparison of transient responses in term of rise time $\mathrm{Tr}$, settling time Ts and percent overshoot $\% \mathrm{Mp}$ are further discussed in section $\mathrm{C}$.

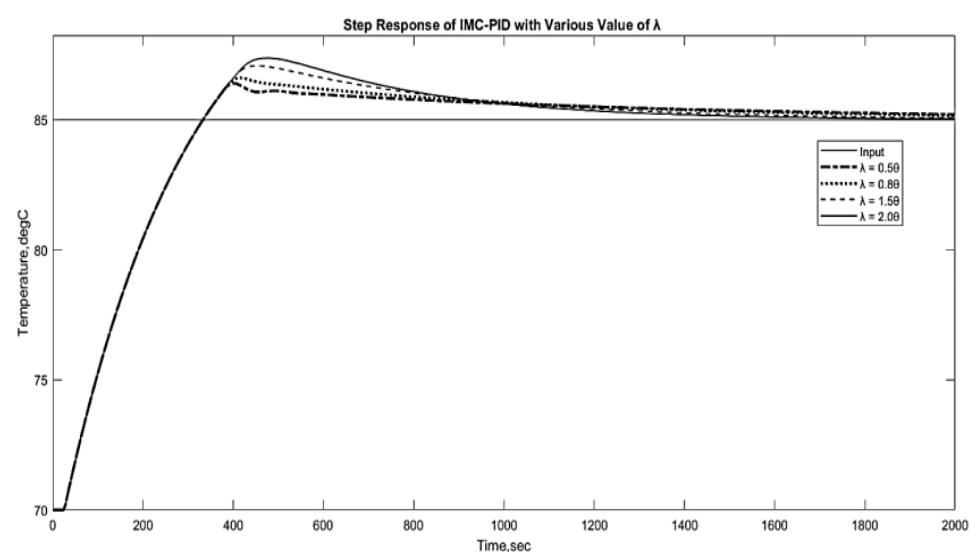

Figure 5: Step response for Saturated IMC-based PID tuning method.

TABLE II

TRANSIENT RESPONSE OF IMC-PID CONTROLLER

\begin{tabular}{|c|c|c|c|}
\hline $\boldsymbol{\Lambda}$ & $\begin{array}{c}\text { RiseTime } \\
\mathbf{T}_{\mathbf{r}} \text { (Second) }\end{array}$ & $\begin{array}{c}\text { Settling Time, } \\
\mathbf{T}_{\mathbf{s}} \text { (Second) }\end{array}$ & $\begin{array}{c}\text { Overshoot } \\
\mathbf{( \% )}\end{array}$ \\
\hline $\boldsymbol{\lambda}=\mathbf{0 . 5 \theta}$ & 237.80 & 834.30 & 7.33 \\
\hline $\boldsymbol{\lambda}=\mathbf{0 . 8 \theta}$ & 237.80 & 916.80 & 10.00 \\
\hline $\boldsymbol{\lambda}=\mathbf{1 . 5 \theta}$ & 237.80 & 929.20 & 14.00 \\
\hline $\boldsymbol{\lambda}=\mathbf{2 . 0 \theta}$ & 237.80 & 930.60 & 15.33 \\
\hline
\end{tabular}

\section{B. IMC-PID Controller with Fractional-Order Filter}

This study evaluates the IMC-PID FOF controller where the design procedure of the controller were proposed by Bettayeb and Mansouri [16], [18]. Fractional-order filter derivative term was approximated using ORA algorithm with $\mathrm{N}=4, \omega_{\mathrm{L}}=0.001$ $\mathrm{rad} / \mathrm{seconds}, \omega_{\mathrm{H}}=10 \mathrm{rad} / \mathrm{seconds}$. The order of derivative function was limited from 0.1 to 0.9 consecutively. The Bode plots of the open-loop system and closed loop-system are shown when $\alpha=0.1$ in Figure 6 and Figure 7 respectively. The calculations of IMC-PID FOF parameter with fractional derivative order from 0.1 until 0.9 were tabulated in Table III. The gain crossover frequency was set in a constant value that were used by Bettayeb and Mansouri [16], [18].

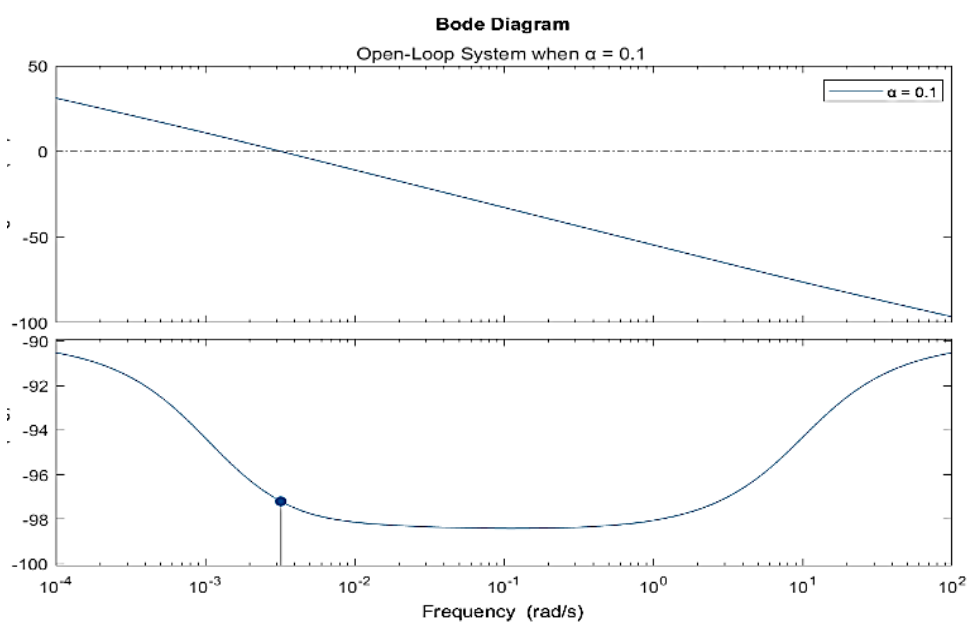

Figure 6: Bode plot of Open-loop system IMC-PID FOF when $\alpha=0.1$

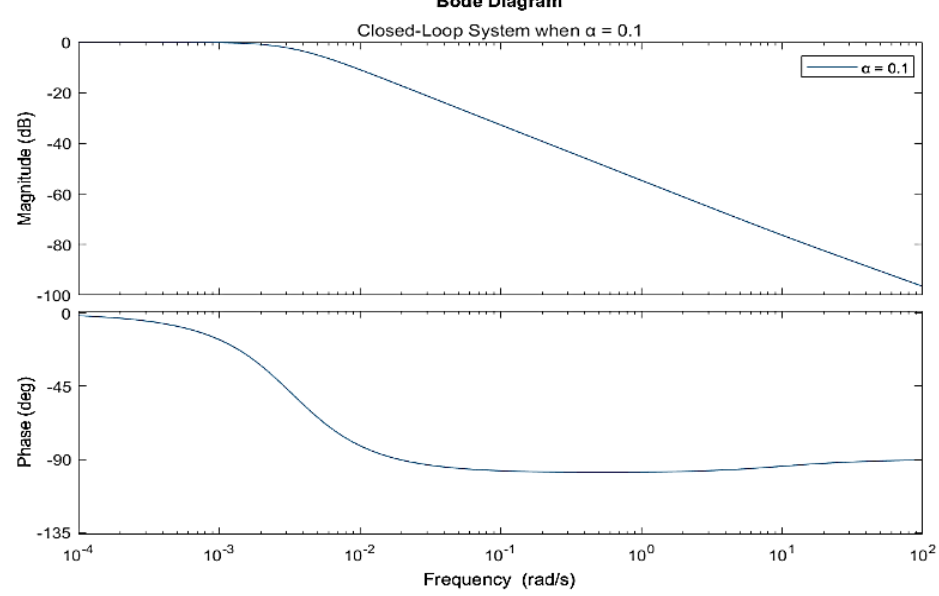

Figure 7: Bode plot of Closed-loop System IMC-PID FOF when $\alpha=0.1$

TABLE III

FRACTIONAL-ORDER FILTER PARAMETER

\begin{tabular}{|c|c|c|c|}
\hline $\mathbf{A}$ & $\begin{array}{c}\boldsymbol{\omega}_{\mathbf{c}}(\mathbf{r a d} / \mathbf{s}) \\
\text { Maâmar\&Rachid } \\
{[\mathbf{1 0 ]}}\end{array}$ & $\begin{array}{c}\boldsymbol{\varphi}_{\mathbf{m}} \\
(\mathbf{d e g})\end{array}$ & $\begin{array}{c}\boldsymbol{\tau}_{\mathbf{c}} \\
\text { (second) }\end{array}$ \\
\hline $\mathbf{0 . 1}$ & 0.008 & 80 & 202.58 \\
\hline $\mathbf{0 . 2}$ & 0.008 & 70 & 328.31 \\
\hline $\mathbf{0 . 3}$ & 0.008 & 60 & 532.08 \\
\hline $\mathbf{0 . 4}$ & 0.008 & 50 & 862.33 \\
\hline $\mathbf{0 . 5}$ & 0.008 & 40 & 1397.50 \\
\hline $\mathbf{0 . 6}$ & 0.008 & 30 & 2264.93 \\
\hline $\mathbf{0 . 7}$ & 0.008 & 20 & 3670.68 \\
\hline $\mathbf{0 . 8}$ & 0.008 & 18 & 5948.91 \\
\hline $\mathbf{0 . 9}$ & 0.008 & 9 & 9641.15 \\
\hline
\end{tabular}

Figure 8 shows the combination of IMC-PID FOF step responses. From the observation of the step response, it shown that IMC-PID FOF with $\alpha=0.7$ produced the highest overshoot of $23.85 \%$ followed by $\alpha=0.5$ of $16.20 \%$. In term of rise time, IMC-PID FOF $\alpha=0.1$ had fastest time of 264.7 seconds compared to 286.9 seconds, 299.0 seconds and 329.20 seconds for $\alpha=0.3, \alpha=0.5, \alpha=0.7$ respectively. Moreover, IMC-PID FOF with $\alpha=0.1$ also had the fastest settling time of 447.00 seconds from all value of $\alpha$. Therefore, IMC-PID FOF with $\alpha=0.1$ has more preferred transient performance compared to other value of 
$\alpha$ due its fastest rise time, settling time and less overshoot. The analysis of the transient responses performances of IMC-PID FOF with fractional derivative order from 0.1 until 0.9 were tabulated in Table IV.

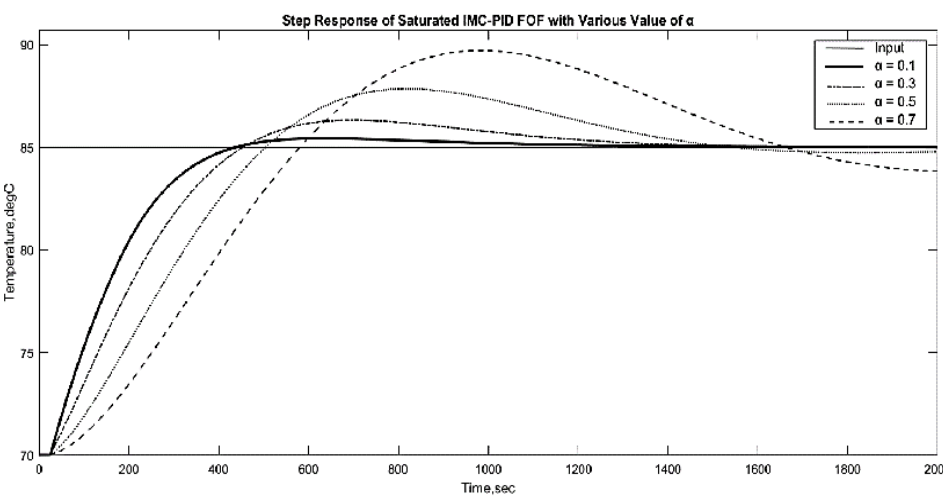

Figure 8: Step Response IMC-PID FOF with variable $\alpha$

TABLE IV

TRANSIENT RESPONSE OF IMC-PID FOF CONTROLLER

\begin{tabular}{|c|c|c|c|}
\hline $\mathbf{A}$ & $\begin{array}{c}\text { Rise Time } \\
\mathbf{T}_{\mathbf{r}} \text { (Second) }\end{array}$ & $\begin{array}{c}\text { Settling Time, } \\
\mathbf{T}_{\mathbf{s}} \text { (Second) }\end{array}$ & $\begin{array}{c}\text { Overshoot } \\
\mathbf{( \% )}\end{array}$ \\
\hline $\mathbf{0 . 1}$ & 264.70 & 447.40 & 2.59 \\
\hline $\mathbf{0 . 2}$ & 284.90 & 462.70 & 4.46 \\
\hline $\mathbf{0 . 3}$ & 299.00 & 989.60 & 7.98 \\
\hline $\mathbf{0 . 4}$ & 329.20 & 1179.90 & 11.76 \\
\hline $\mathbf{0 . 5}$ & 347.30 & 1302.40 & 16.20 \\
\hline $\mathbf{0 . 6}$ & 371.50 & 1436.60 & 19.77 \\
\hline $\mathbf{0 . 7}$ & 395.80 & 1558.10 & 23.85 \\
\hline $\mathbf{0 . 8}$ & 424.70 & 1676.50 & 27.53 \\
\hline $\mathbf{0 . 9}$ & 443.5 & 1808.10 & 31.15 \\
\hline
\end{tabular}

\section{Controllers Comparison Studies of Transient Responses}

In this section, comparative studies of transient responses were conducted to compare the controllers. The comparison was also included the CIMC-PID controller proposed by Chien et al [27]. In their findings, it was shown CIMC-PID controller was more robust than the tuning rules of Ziegler-Nichols and Cohencoon for PID controller. The tuning rules also successfully applied to an industrial process with FOPDT model. Thus, CIMC-PID was chosen as one type of controller to be compared.

Figure 9 shows the step response of these controllers. As can be observed, IMC-PID FOF provides better performance in terms of the transient response. The transient responses were listed in Table IV.

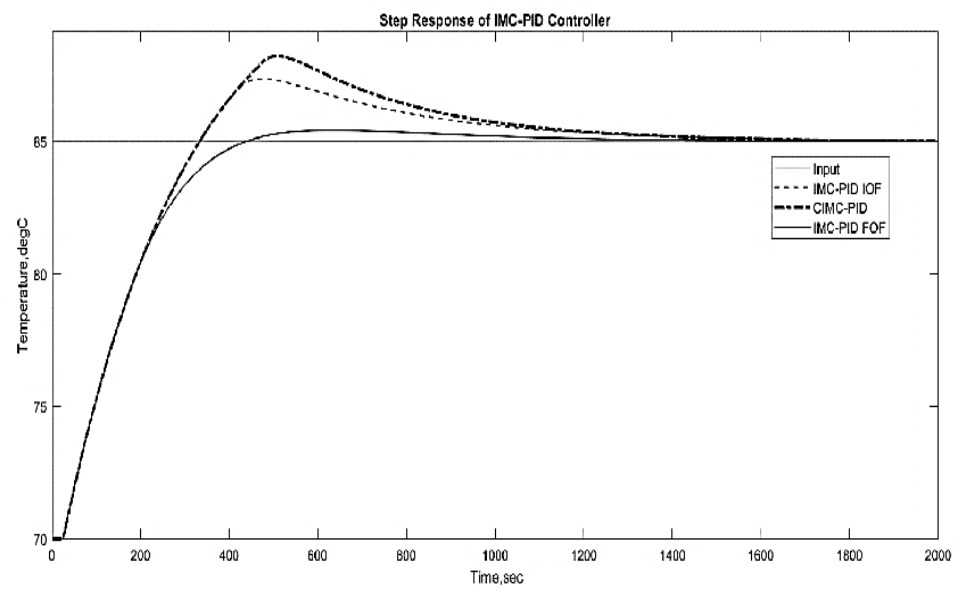

Figure 9: Step Response IMC-PID Controller
TABLE IV

COMPARISON OF TRASIENT RESPONSE IN VARIOUS RANGE OF $\lambda$

\begin{tabular}{|c|c|c|c|}
\hline Controller & $\begin{array}{c}\text { Rise time } \\
\text { (sec) }\end{array}$ & $\begin{array}{c}\text { Settling } \\
\text { Time (sec) }\end{array}$ & Overshoot (\%) \\
\hline IMC-PID FOF & 264.70 & 447.40 & 2.59 \\
\hline IMC-PID & 237.80 & 930.60 & 15.33 \\
\hline CIMC-PID & 250.00 & 992.00 & 21.33 \\
\hline
\end{tabular}

Figure 10 shows the control output obtained with IMCPID, CIMC-PID and IMC-PID FOF controllers. One can observe the advantage of IMC-PID FOF controller where the signal is much smoother than other IMC-PID controllers.

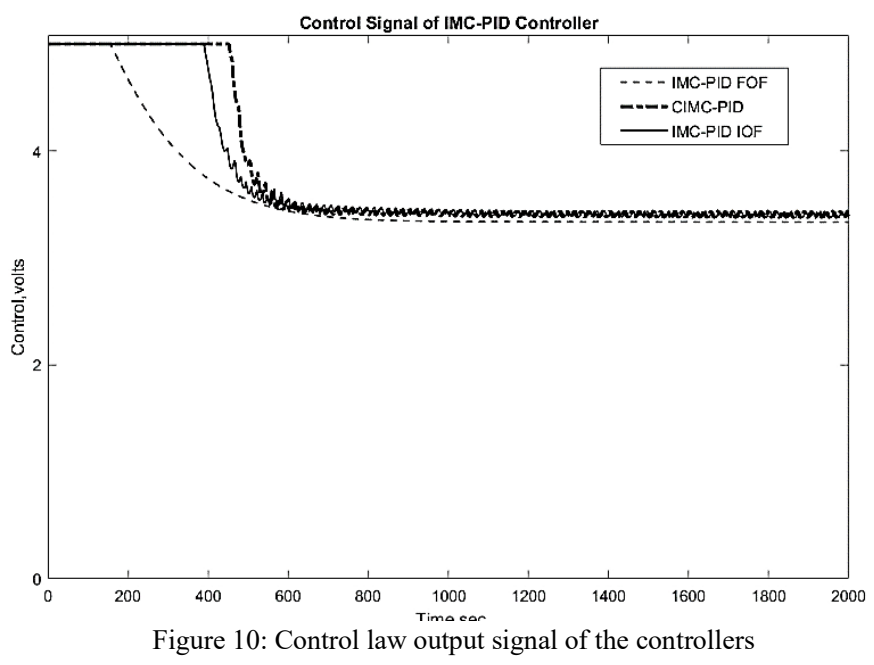

\section{CONCLUSION}

This paper presented the study between IMC-PID controller with integer-order filter (IOF) and fractional-order filter (FOF) design for the SDEOE. The aim of this paper is to compare the transient response of these two controllers respective to steam temperature in SDEOE. It consisted of a conventional controller based on an IMC paradigm, cascaded with two different filters. IMC-PID IOF controller had the sole tuning parameter which is closed loop time-constant $\lambda$. IMC-PID FOF controller had two parameters which are the time constant $\tau_{\mathrm{c}}$ and non-integer parameter of fractional order, $\alpha$ of which had been tuned to obtain the desired overshoot (depends on $\alpha$ ) and desired settling time (depends on time constant, $\tau_{\mathrm{c}}$ ). This give extra advantages to IMC-PID FOF controller due to its flexibility towards the system. Other advantages of IMC-PID FOF controller compared to IMC-PID IOF and CIMC-PID controllers was it had a fastest response and less overshoot because of the iso-damping robustness property despite of the controller tuning complexity. It can be shown in the result that reducing of percent overshoot from CIMC-PID controller by $21.33 \%$ to $2.59 \%$ produced by IMC-PID FOF controller. In terms of settling time Ts, IMC-PID FOF controller had the fastest time with approximately 480-550 seconds fastest than both controllers.

\section{ACKNOWLEDGMENT}

The authors like to express our gratitude to Faculty of Electrical Engineering, Universiti Teknologi MARA Shah Alam and IRMI through BESTARI (Reference Code:600-IRMI/DANA 5/3/BESTARI $(049 / 2017)$ internal fund for the funding and facilities. 


\section{REFERENCES}

[1] S. Maharaj and D. McGaw, "Mathematical Model For The Removal Of Essential Oil Constituents During Steam Distillation Extraction," Processes, vol. 8, no. 4, p. 400, 2020.

[2] S. Hamzeh, R. Safari-Faramani, and A. Khatony, "Effects of Aromatherapy with Lavender and Peppermint Essential Oils on the Sleep Quality of Cancer Patients: A Randomized Controlled Trial," Evidence-Based Complement. Altern. Med., vol. 2020, pp. 1-7, 2020.

[3] S. Ataei, P. Azari, A. Hassan, B. Pingguan-Murphy, R. Yahya, and F. Muhamad, "Essential Oils-Loaded Electrospun Biopolymers: A Future Perspective for Active Food Packaging," Adv. Polym. Technol., vol. 2020, pp. 1-21, 2020 .

[4] Q. W. Zhang, L. G. Lin, and W. C. Ye, "Techniques for extraction and isolation of natural products: A comprehensive review," Chinese Med. (United Kingdom), vol. 13, no. 1, pp. 1-26, 2018.

[5] J. Mulvaney, "Essential Oils and Steam Distillation," J. New Zeal. Assoc. Med. Herbalists, vol. 24, no. 4, pp. 15-19, 2012.

[6] M. Tajjudin, M. H. F. Rahiman, N. Ishak, H. Ismail, N. M. Arshad, and R. Adnan, "Adaptive Steam Temperature Regulation for Essential Oil Extraction Process," Int. J. Control Sci. Eng., vol. 2, no. 5, pp. 111119, 2012.

[7] N. Kasuan, Z. Yusuf, M. N. Taib, M. H. F. Rahiman, N. Tajuddin, and M. A. A. Aziz, "Robust steam temperature regulation for distillation of essential oil extraction process using hybrid fuzzy-PD plus PID Controller," World Acad. Sci. Eng. Technol., vol. 71, no. 11, pp. 932937, 2010.

[8] H. H. A. Rassem, A. H. Nour, and R. M. Yunus, "Techniques For Extraction of Essential Oils From Plants: A Review," Aust. J. Basic Appl. Sci., vol. 10, no. 16, pp. 117-127, 2016.

[9] B. W. Bequette, "The IMC-Based PID Procedure.7," Prentice Hall Int. Ser. Phys. Chem. Eng. Sci., pp. 163-190, 1999.

10] H. Yin, W. Zhang, R. Yao, and S. Lin, "IMC-PID Load Disturbance Rejection Controller with Set-point Filter for The Integrating and Unstable Processes with Time delay," 2018 37th Chinese Control Conf., pp. 142-147, 2018.

[11] R. Daniel, M. Morari, and S. Skogestad, "Internal Model Control.4.PID Controller Design," Chem. Eng., vol. 25, no. 1, pp. 252265, 1988.

[12] I. G. Horn, J. R. Arulandu, C. J. Gombas, J. G. Vanantwerp, and R. D. Braatz, "Improved filter design in internal model control," Ind. Eng. Chem. Res., vol. 35, no. 10, pp. 3437-3441, 1996.

[13] S. Skogestad, "Probably the best simple PID tuning rules in the world," J. Process Control July, vol. 13, pp. 291-309, 2001.

[14] X. F. Li, D. J. Ding, Y. G. Wang, and Z. Huang, "Cascade IMC-PID Control of Superheated Steam Temperature based on Closed-loop Identification in the Frequency Domain," IFAC-PapersOnLine, vol. 49, no. 18, pp. 91-97, 2016.

[15] S. Skogestad and C. Grimholt, "The SIMC method for smooth PID controller tuning.5," Adv. Ind. Control, no. 9781447124245, pp. 147$175,2012$.

[16] M. Bettayeb and R. Mansouri, "IMC-PID-fractional-order- filter controllers design for integer order systems," ISA Trans., vol. 53, no. 5, pp. 1620-1628, 2014.

[17] A. Oustaloup, "Crone Control: Principle,Synthesis,Performances with Non-Linearities and Robustness-Input Immunity Dilemma," J. Chem. Inf. Model., vol. 53, no. 9, 1999.

[18] M. Bettayeb and R. Mansouri, "Fractional IMC-PID-filter controllers design for non integer order systems," J. Process Control, vol. 24, no. 4, pp. 261-271, 2014.

[19] R. Ranganayakulu, A. Seshagiri Rao, and G. Uday Bhaskar Babu, "An Improved fractional filter IMC-PID controller design for enhanced performance of integrating plus time delay processes," Indian Chem. Eng., vol. 21, no. 2, pp. 139-147, 2019.

[20] M. Tajjudin, M. H. F. Rahiman, N. Mohd Arshad, and R. Adnan, "Robust Fractional-Order PI Controller with Ziegler-Nichols Rules Mazidah," World Acad. Sci. Eng. Technol. Int. J. Electr. Comput. Eng., vol. 7, no. 7, pp. 1523-1530, 2013.

[21] C. E. Garcia and M. Morari, "Internal Model Control. 2. Design Procedure for Multivariable Systems," Ind. Eng. Chem. Process Des. Dev., vol. 24, no. 2, pp. 472-484, 1985.

[22] E. Zafiriou and M. Morari, "Robust H 2 -Type IMC Controller Design via the Structured Singular Value," IFAC Proc. Vol., vol. 20, no. 5, pp. 259-264, 1987.

[23] A. K. Shah, M. Anilkumar, and N. Parikh, "Performance Analysis ofIMC based PID controller tuning on Approximated Process
Performance analysis of IMC based PID controller tuning on approximated process model," Nirma Univ. J. Eng. Technol., vol. 1, no. 2, pp. 51-54, 2010

[24] H. W.BODE, "Network Analysis and Feedback Amplifier design," New Work Van Nostrand, vol. 10, 1945.

[25] C. A. Monje, B. M. Vinagre, V. Feliu, and Y. Q. Chen, "Tuning and auto-tuning of fractional order controllers for industry applications," Control Eng. Pract., vol. 16, no. 7, pp. 798-812, 2008.

[26] F. Merrikh-Bayat, "Rules for selecting the parameters of Oustaloup recursive approximation for the simulation of linear feedback systems containing PI $\lambda \mathrm{D} \mu$ controller," Commun. Nonlinear Sci. Numer. Simul., vol. 17, no. 4, pp. 1852-1861, 2012.

[27] P. S. Fruehauf, I. L. Chien, and M. D. Lauritsen, "Simplified IMC-PID tuning rules," ISA Trans., vol. 33, no. 1, pp. 43-59, 1994. 